\title{
Identification and Monitoring the Change of Land Use Pattern Using Remote Sensing and GIS: A Case Study of Dhaka City
}

\author{
Abdullah Al Mamun ${ }^{1}$, Asif Mahmood ${ }^{2}$, Mafizur Rahman ${ }^{3}$ \\ ${ }^{1}$ (Department of Civil Engineering, Bangladesh University of Engineering and Technology, Bangladesh) \\ ${ }^{2}$ (Department of Civil Engineering, Bangladesh University of Engineering and Technology, Bangladesh) \\ ${ }_{3}^{3}$ (Professor, Department of Civil Engineering, Bangladesh University of Engineering and Technology, \\ Bangladesh)
}

\begin{abstract}
Dhaka is one of the fastest growing megacities of the world with a dense population over 15 million. Being the capital of a developing country like Bangladesh, it is experiencing multi-dimensional problems such as over urbanization, traffic congestion, water logging, solid waste disposal, black smoke from brick kilns and industrial emissions, sound pollution, pollution of water bodies by industrial discharge and the newly added calamity, building collapse. Dhaka is a sheer example of having poor legislative actions, inefficient management and lack of public awareness, which leads the urbanization to an unplanned and resource consuming development. This paper presents an integrated study of urbanization trends in Dhaka City, Bangladesh, by using Geographical Information Systems (GIS) and Remote Sensing (RS). This study explores the land use change pattern of Dhaka City Corporation over 1990-2010, through interactive supervised land cover classification using Landsat images by ArcGIS 10. The remotely detected land use/cover change from 1990 to 2010 shows that Dhaka is gradually changing as vegetative cover and open spaces have been transformed into building areas, low land and water bodies into reclaimed built up lands. These changes are mainly governed by unplanned urban expansion.
\end{abstract}

Keywords - ArcGIS 10.0, Dhaka City Corporation, GIS, Land Use Pattern, Remote Sensing.

\section{Introduction}

Urbanization is a term representing the basic transformation of information, technology, culture and moreover people into developed mass and thus it can create a hazard if it is not maintained systematically.

Since land use/land cover change is a major factor for global change because of its interactions with climate, ecosystem processes, biogeochemical cycles, biodiversity and even more important, human activities, land use/land cover change researches has become an important aspect of global change, or global warming studies in recent decades [1][2]. Much more attention has been paid to urban land use/land cover change in the last 10 years, because ecosystems in urban areas are strongly affected by human activities and have close relations with the life of almost half of the world's population [3].

For measuring qualitative and quantitative terrestrial land-cover changes, satellite imagery has been well utilized in the natural science communities [4][5][6]. Both qualitative and quantitative changes in landcover have been successfully monitored with remote sensing, with research dominated by efforts at monitoring change in vegetation and forest canopies [5][7].

Remote sensing provides spatially consistent data sets that cover large areas with both high spatial detail and high temporal frequency. Dating back to 1960, remote sensing can also provide consistent historical time series data. The importance of remote sensing was emphasized as a "unique view" of the spatial and temporal dynamics of the processes in urban growth and land use change [8]. Satellite remote sensing techniques have, therefore, been widely used in detecting and monitoring land cover change at various scales with useful results [9][10]. Recently, remote sensing has been used in combination with Geographical Information Systems (GIS) and Global Positioning Systems (GPS) to assess land cover change more effectively than by remote sensing data only [11][12]. It has already proved useful in mapping urban areas, and as data source for the analysis and modeling of urban growth and land use/land cover change [8][10][13].

Like other developing countries, Bangladesh experienced a fast increase of urban population in the recent decades: 14.1 million in 1981, 22.5 million in 1991, 31.1 million in 2001, and 35 million in 2005 [14]. Rapid urban growth leads to the transformation of rural lands to built-up areas, and it is estimated that each year more than $809 \mathrm{~km}^{2}$ of agricultural land is being diverted to cities, roads and infrastructures in Bangladesh [15]. As agriculture is the life of national economy, loss of cultivated land becomes great concern that can contribute to the increase of landlessness and jeopardizing the economy. Furthermore, food shortage could be acute in the coming years, and it would be a great hurdle for Bangladesh to meet up the rising food demand for its ever growing population. 
Dhaka, the capital of Bangladesh could be the best illustration of human activities and associated environmental change. Dhaka is expanding apace, at an average rate of $4.24 \% / y e a r$ and is projected to be the third largest megacity in the world by the year 2020 [16]. The growth of the city is phenomenal after independence [17] and highest among other cities in Bangladesh due to its socio-economic and political importance. The growth is mainly attributed to the large influx of rural to urban migration [18].

While current and accurate information on land use/cover is a prerequisite to the management and planning of urban areas, data paucity and lack of up-to-date information on land use/cover exist in Dhaka. Sustainable urban development cannot be achieved in the absence of such information, and may lead to the mismanagement of scarce resources which is prevalent in Dhaka [19]. Thus, space-borne remotely sensed data is deemed to be predominantly important for Dhaka Metropolitan, as there is a lack of consistent spatial information. To achieve sustainable urban development and to derive sound environmental planning, timely and reliable land cover information is not only imperative to comprehend the past and present condition of the land but also used to facilitate the development of integrated resource management policies [20].

Previously Basak [21], Griffiths [22], Dewan and Yamaguchi [23] and Bayes [24] - all have classified the land cover types of Dhaka city using multi-temporal satellite images by remote sensing and GIS for different periods of time. They have also used a post-classifier for the post-evaluation of land cover types.

In this study, we use the spatial analysis function of GIS to classify 1990, 2003 \& 2010 Landset image of Dhaka city and evaluate the land use and land cover change that occurred in the last two decades. Specifically, the aim of this paper is to dynamically map and monitor the land use/cover change and to analyze the changes with respect to the baseline of 1990.

\section{Study Area Profile}

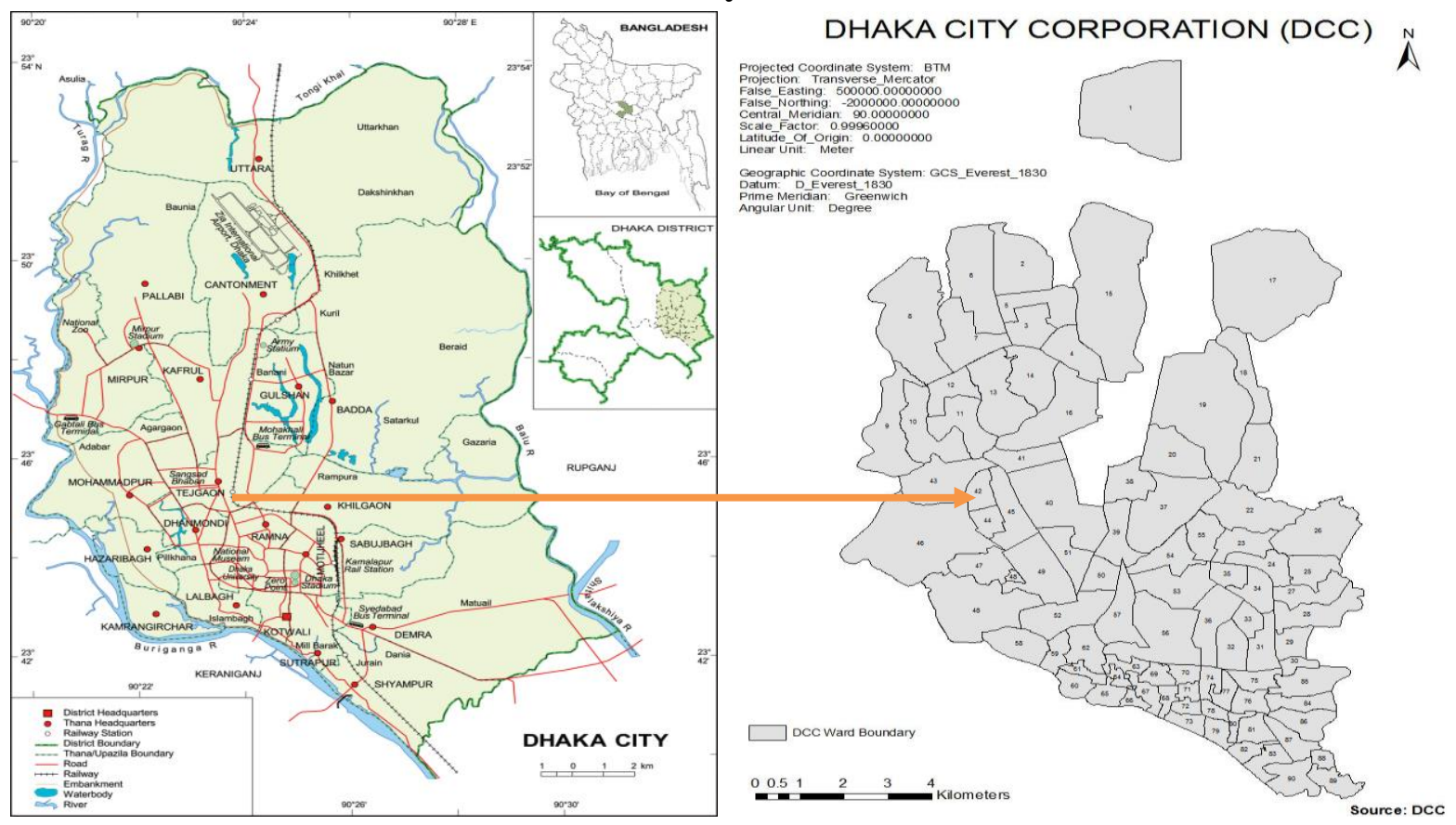

Figure 1 Location of study area

There are 64 districts in Bangladesh. Dhaka City is located in Dhaka District that is surrounded by rivers. Dhaka is located in central Bangladesh at $23^{\circ} 43^{\prime} 0^{\prime \prime} \mathrm{N}, 90^{\circ} 24^{\prime} 0^{\prime \prime} \mathrm{E}$, on the eastern banks of the Buriganga River. Dhaka city area is under jurisdiction of different authorities that are known as Dhaka City Corporation (DCC), Dhaka Metropolitan Area (DMA), Dhaka Statistical Metropolitan Area (DSMA) and Dhaka Metropolitan Development Plan (DMDP) area.

The proposed study area for this study is Dhaka City Corporation (DCC) and its surrounding impact areas (Fig. 1). The study area covers the oldest organic core part of Dhaka city (old Dhaka), the planned areas and even the unplanned new generation organic areas that are called 'Informal Settlements'. This selected study area almost covers the biggest urban agglomeration and is the central part of Bangladesh in terms of social and economic aspects. Therefore, this area has huge potentiality to face massive urban growth in near future based on the current trend of rapid urbanization. 


\subsection{Data Collection}

\section{Data And Methodology}

This research is dependent on secondary data. To prepare the base maps for analysis purpose and applying the different methods to achieve the study objectives, Landsat satellite images ( 1990, 2003 and 2010 ) have been collected from Bangladesh Space Research \& Remote Sensing Organization (SPARSO). Table 2.1 shows the details of the Landsat satellite images used for analysis.

Table 1 Details of Landsat Satellite Images

\begin{tabular}{|c|c|c|}
\hline $\begin{array}{l}\text { Respective } \\
\text { Year }\end{array}$ & $\begin{array}{c}\text { Date Acquired } \\
\text { (Day/Month/Year) }\end{array}$ & Sensor \\
\hline 1990 & 07-01-1990 & Landsat-5-TM \\
\hline 2003 & $24-03-2003$ & Landsat-7-ETM+ \\
\hline 2010 & $30-01-2010$ & Landsat-5-TM \\
\hline
\end{tabular}

Map Projection of the collected satellite images is Universal Transverse Mercator (UTM) within Zone 46 N- Datum and of the co-ordinate system World Geodetic System (WGS) 84 and the pixel size is 30 meters.

For the purpose of obtaining the study area (i.e. DCC ), the GIS format file (i.e. shape file) of DCC has been collected from IWM (Institute of Water Modeling), Bangladesh. For the purpose of referencing, several base maps of Dhaka City have been collected from the Survey of Bangladesh (SoB). The land use maps of all the wards of DCC (2008) have been collected from DCC and Rajdhani Unnayan Kartripakkha (RAJUK) or Capital City Planning and Development Authority. Google Earth is another option to get some ideas about the recent land cover pattern of Dhaka city. These reference data have been used for training site selection and preparing land cover maps.

\subsection{Data Preparation}

The collected images are pre-processed by radiometric or geometric corrections. Radiometric corrections include correcting the data for sensor irregularities and unwanted sensor or atmospheric noise, and converting the data so they accurately represent the reflected or emitted radiation measured by the sensor.

Image enhancement is solely to improve the appearance of the imagery to assist in visual interpretation and analysis. Contrast stretching has been performed to increase the tonal distinction between various features in a scene, and spatial filtering to enhance (or suppress) specific spatial patterns in an image. Arithmetic operations (i.e. subtraction, addition, multiplication, division) are performed to combine and transform the original bands into "new" images which better display or highlight certain features in the scene. The image pre-processing, enhancement and transformation operations are done using ERDAS IMAGINE 9.1.

To segregate the study area from the images, geo-referencing of the satellite images have been performed. They are transformed to the Bangladesh Transverse Mercator (BTM) map projection system with datum D_Everest_1830 as same as the DCC shape file. Then images are cropped by the Extraction tool under Spatial Analyst Tools of ArcToolbox in ArcGIS 10.0.

\subsection{Land Use/Cover Classification}

Using the basic colors red, green and blue (RGB), it is possible to prepare different FCC images [25]. To distinguish between different cover types or ground objects like buildings, roads, and vegetation, these FCC images are useful. We have choose the FCC of $\mathrm{RGB}=$ bands 4,3 and 2 for this study. This combination normally makes built-up areas appear blue, vegetation red, water bodies from dark blue to black, soils with no vegetation from white to brown [26].

Image classification refers to grouping image pixels into categories or classes to produce a thematic representation [27]. Image classification comprehends various operations that can be applied to photographic or image data. These include image restoration, image pre-processing, enhancement, compression, spatial filtering, and pattern recognition and so on [27]. There are two basic methods of image classification: supervised and unsupervised [25]. Supervised classification relies on the priori knowledge of the study area [27]. Therefore, for this study, a supervised classification method has been used.

\subsubsection{Training Site Development}

In a supervised classification, an image is classified using polygons that represent distinct sample areas of the different land use types to be classified (training samples). In previous releases, training samples were collected by first having to create a polygon feature class and then having to edit the feature class using the Editor Toolbar. In ArcGIS 10, this task has been made much easier by editing of training samples with the 
Image Classification toolbar. Training samples of four specific classes are taken for the classification. The designation and covering features of each class are shown in Table 2.

Table 2 Details of the Land Cover Types

\section{Land use/cover types}

Water bodies and Wetlands

$$
\text { Built-up }
$$

Vegetation and cultivated land

Bare soil/Exposed soil

\section{Description}

River, permanent open water, lakes, ponds and reservoirs ;Permanent and seasonal wetlands, marshy land, rills and gully, swamps

Residential, commercial and services, industrial, transportation, roads, mixed urban, and other urban

Deciduous forest, mixed forest lands, palms, conifer, scrub and others Crop fields, fallow lands and vegetable lands

Exposed soils, sand fill, landfill sites, and areas of active excavation

As many as required samples are taken for a definite class and finally they are merged. Samples of other classes have been taken accordingly. In this study, the training samples have been selected relying on the real time data. To do this, help of Google Earth Software is taken. All the image files (i.e. .img files) are converted to Google Earth supported .kml files including the transformation of datum to WGS 84. Then the kml format file of one year, say, of the year 2003 is opened on Google Earth and it has been merged over the Google Earth image of Dhaka of March, 2003. Finally, training samples are accurately developed on the basis of Google Earth image. This procedure for developing training samples is repeated for each respective year. In the following, Fig. 3 summarizes the procedure of training site development.

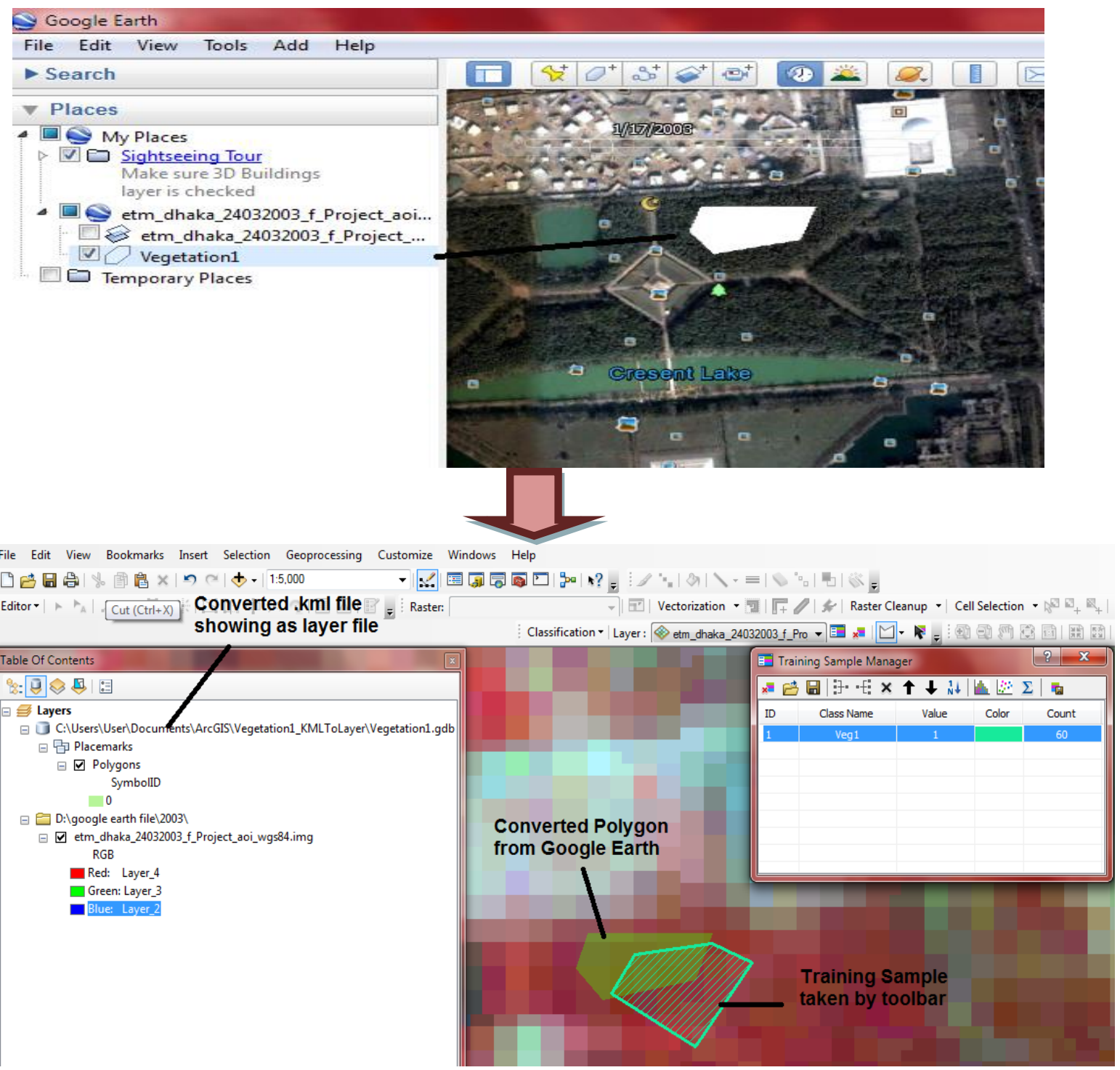

Figure 2 Procedure of developing training samples by google earth polygons 
In this study, training samples are developed considering all the variations of pixel brightness of a specific class. Beside this, for the seasonal variation and variation in type of Landsat images, uneven distribution of the training samples for different years has been occurred. Fig. 3 shows the positioning of the training samples in different years.

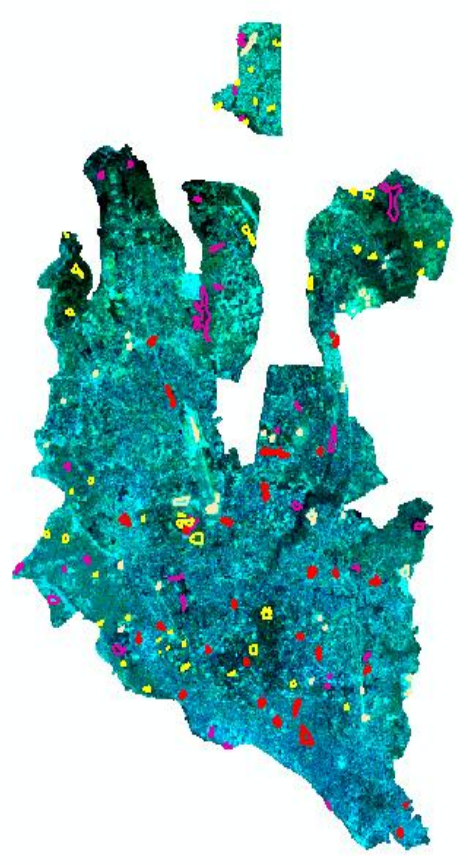

1990

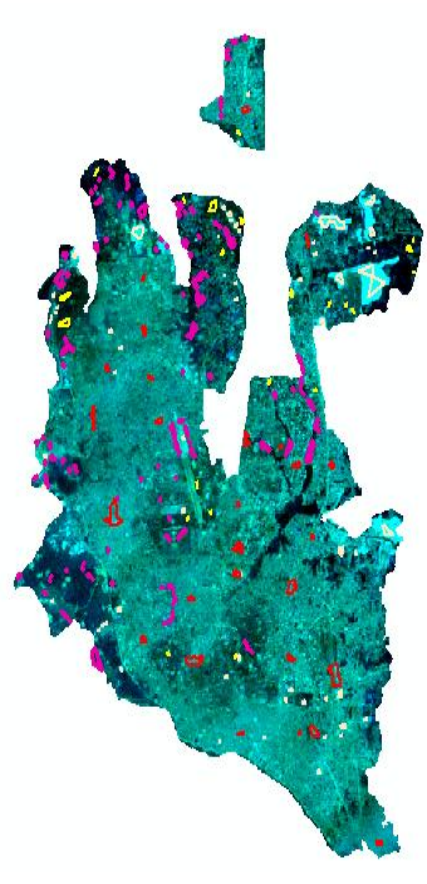

2003

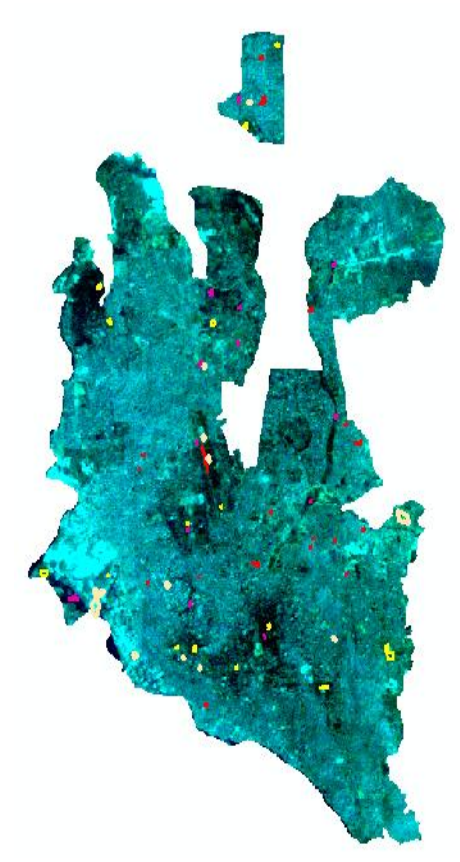

2010



\section{LEGEND:}

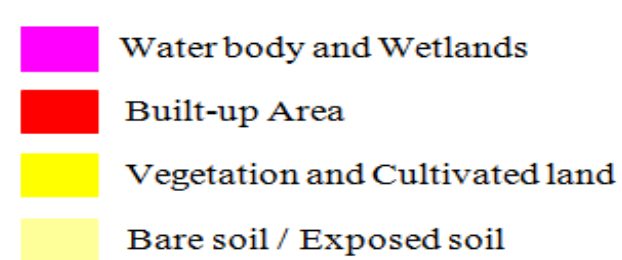

Figure 3 Location of training samples

\subsubsection{Image Classification}

After developing training samples for all land cover classes the next step is to classify the images based on these training samples. This has been done using the Interactive Supervised Classification Toolbar in ArcGIS 10.0. This latest version of ArcGIS enables us to perform the land cover classification without creating any signature files, which was primitive for the older versions.

\subsubsection{Generalization}

Sometimes many isolated pixels may be found after image classification [25]. These isolated pixels belong to one or more classes that differ from surrounding pixels. Therefore it is necessary to generalize the image and remove the isolated pixels. Filtering is the solution for this type of problem [25]. After a vector-toraster conversion, mode filters are good for filling gaps between polygons. Therefore, a $3 \times 3$ mode filter has been applied to generalize the supervised classified land cover images. This post-processing operation replaces the isolated pixels to the most common neighboring class. Finally the generalized image is reclassified to produce the final version of land cover maps for 1990, 2003 and 2010, shown in Fig. 4. 


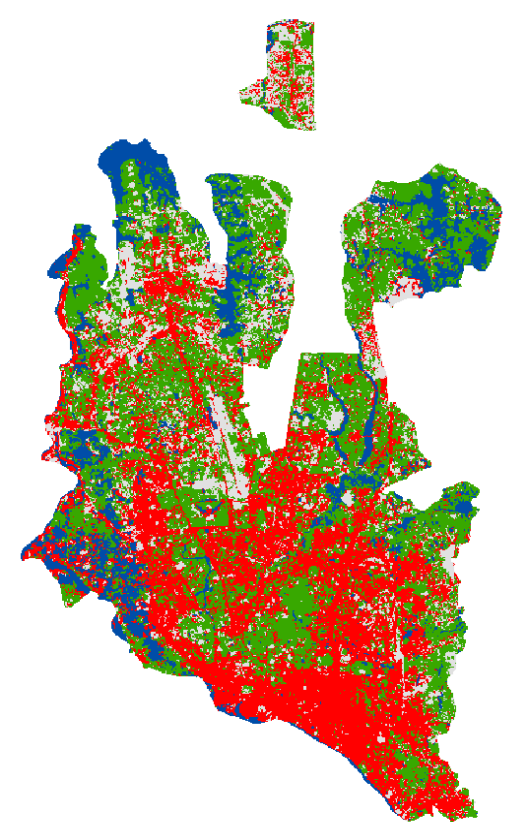

LEGEND:
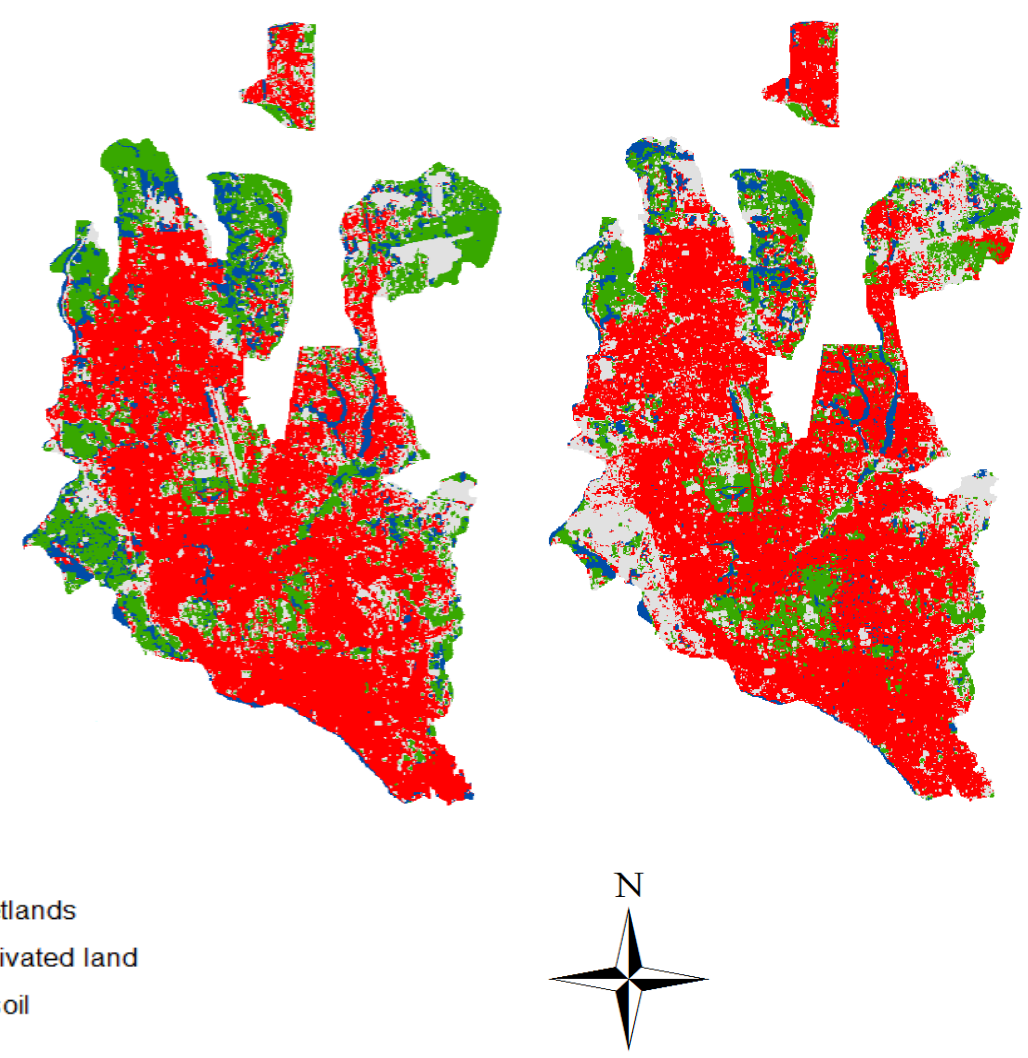

Figure 4 Land cover map of the years 1990, 2003 and 2010

\section{Identification And Monitoring Of Land Use Change Pattern}

Table 3 shows the area obtained from the land cover classification of four types (i.e. Water body and Wetland, Built-up, Vegetation and Cultivated land, Bare soil/ Landfill) and their percentage of total area. Temporal pattern of land use/cover from 1990 to 2010 in Dhaka City Corporation of Bangladesh are shown in Fig. 5.

Table 3 Summary of land cover classification statistics between 1990 and 2010 (area in hectares)

\begin{tabular}{|c|c|c|c|c|c|c|}
\hline $\begin{array}{c}\text { Land use/cover } \\
\text { types }\end{array}$ & \multicolumn{2}{|c|}{1990} & \multicolumn{2}{c|}{2003} & \multicolumn{2}{c|}{2010} \\
\hline $\begin{array}{c}\text { Water body and } \\
\text { Wetland }\end{array}$ & 1715.4 & 12.33 & 1166 & 8.38 & 799.65 & 5.74 \\
\hline $\begin{array}{c}\text { Built-up } \\
\text { Vegetation and }\end{array}$ & 4759.92 & 34.20 & 7268.4 & 52.25 & 7970.67 & 57.26 \\
\hline $\begin{array}{c}\text { Cultivated land } \\
\text { Bare soil/ }\end{array}$ & 5414.67 & 38.91 & 3009.6 & 21.63 & 2232.63 & 16.04 \\
\hline Exposed soil & 2026.71 & 14.56 & 2467.9 & 17.74 & 2917.44 & 20.96 \\
\hline
\end{tabular}

Spatial patterns of land cover shows that urban growth followed certain directions between 1990s and 2010s depending on the ground elevation. For example, the earlier direction of the growth of built-up land was followed by north, north-west, and west trends but the current trend shows a horizontal expansion (Fig. 4). Historically, the direction of urban expansion of Dhaka has greatly been constrained by the low elevation of lands, surrounding rivers, and flooding risk. Thus high and medium terraces were subjected to major development, usually not liable to inundation. The interpretation of the 2003 and 2010 land cover maps, however indicated that Dhaka is being started to expand in all directions, specifically to north-east, south-east and southern parts by filling up low lying areas. In order to lessen the flood susceptibility, earth filling is a very popular means of land development in DCC. Three sectors, namely, public, private and individual households are responsible for rapid land use/cover change in Dhaka. Earlier land developments were mainly done by ad- 
hoc planning by the public sector mainly onto agricultural lands. Currently, a tremendous increase of private sectors, particularly real state agencies, is noticeable in Dhaka, developing both wetlands and agricultural lands without considering the environmental consequences. Also, land conversion by individual for speculative purposes has greatly been influencing the development of suburb areas as observed during field visits.



Figure 5 Temporal pattern of land use/cover change

Furthermore, poor coordination among the organizations is equally accountable to the quick loss of natural covers. For instance, approximately 6,000 ha of Dhaka-Narayangonj-Demra (DND) project were originally retained for assisting the agricultural production, which is being converted to residential land apace since 1990s without any approval from the government [18]. This unauthorized land conversion is clearly implying the weakness of the involvement of multiple legislative agencies. Hence, unregulated expansion in Dhaka City Corporation is underway, and leading to unauthorized growth.

The nature of land cover changes revealed that the built-up and bare soil/landfill categories have been increased significantly (Table 3). Fig. 5 can be used to discern the incredible pressure of urbanization on natural land covers in Dhaka City Corporation. Table 3 demonstrates that between 1990 and 2010, urban built-up areas increased approximately 3210 ha with an increase of around 890 ha in bare soil/landfill while vegetation and cultivated land decreased 3180 ha, wetland/lowland and water bodies decreased 915 ha. This result affirms the earlier findings made by different researchers using supervised classification by ArcGIS [23][24].

To accommodate the increasing population, the city has been expanded extensively compared to its early stage and concurrently its spatial expansion has been severely constrained by the physical factors. Therefore most of the development has been resulted in the loss of natural resources. It has been observed that the growth of Dhaka is extremely faster than the megacities of North America and Europe. A basic difference is noticed in the case of Dhaka's growth. For example, mega cities in the western world grew gradually which enables these cities to effectively develop the necessary services and management facilities for its people but the situation is just opposite in Dhaka city due to the extreme pressure of population explosion. Consequently, local government is confronting diverse challenges to attain sustainable development which could be more acute in the coming years if planning regulations are not enforced. To evaluate the results of land cover conversion, matrices of land cover change from 1990 to 2003, 2003 to 2010, and 1990 to 2010 were calculated and relative changes between years have been determined (Fig. 4).

If we look up to the trend of land use transformation, it can be seen that vegetation to built-up, wetlands to bare soil and then to built-up transformations are prominent (Fig. 4; Fig. 6). This calculation revealed that cultivated land and vegetation was used for urban development in the 1990-2003 and 2003-2010, accordingly resulted in 44\% and 26\% loss. Also, from 1990 to 2003 and 2003 to 2010, water bodies and mainly wetlands (i.e. $32 \%$ and $31 \%$ loss) were converted to bare-soils (i.e. $22 \%$ and $18 \%$ gain) and then to built-up areas (i.e. $53 \%$ and $10 \%$ gain). 


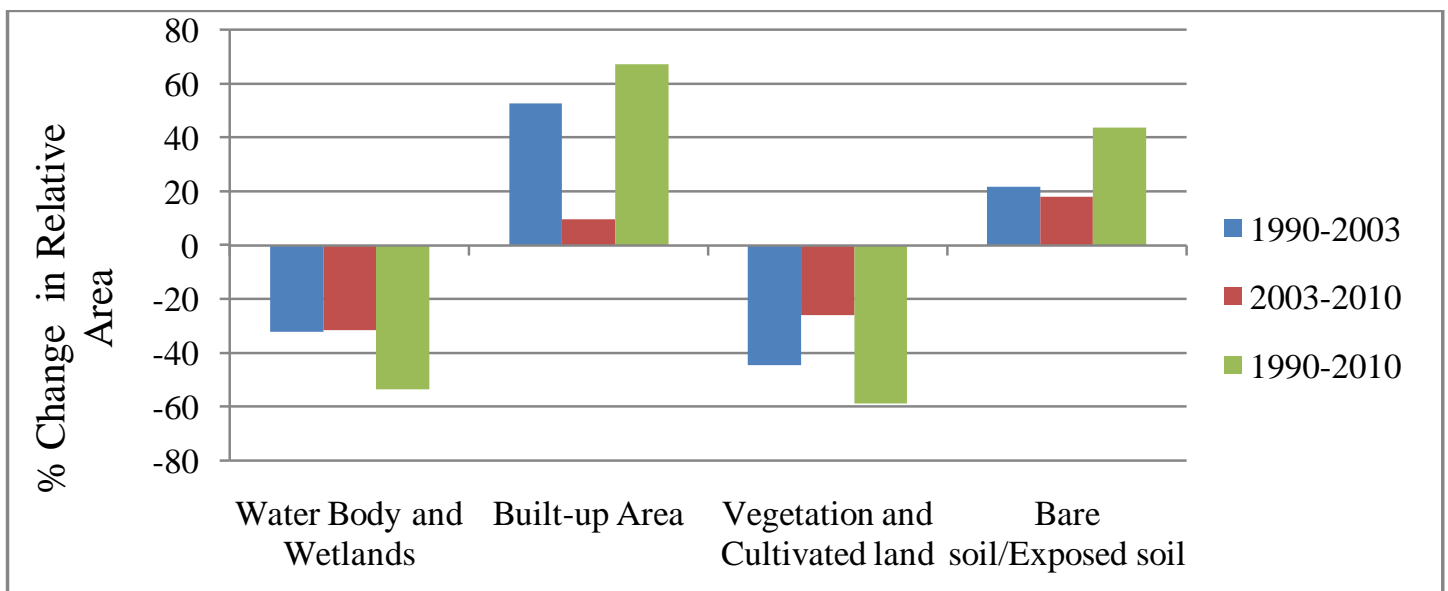

Figure 6 Relative changes in land cover (\%) in DCC

During 1990-2003, the conversion pressure was mainly onto cultivated land and vegetation as it shows the maximum loss. But in case of 2003-2010, the pressure transferred to wetlands as near all cultivated lands had already been converted to built-up areas.

Urbanization in the study area has been very rapid on other land covers with discontinuous patches which resulted in diversified and uneven expansion. Inadequate housing, unplanned and haphazard development, ubiquitous urban poverty, absence of proper land use policy, inequity of lands, pitiable coordination among responsible organizations and absence of reliable information on the current land use practice, all are contributing to the urban sprawling which is leading to the unconceivable emergence of slums and squatters. It is estimated that presently about 37\% of the city's population live in slums [28] and the environment of slum is extremely unhygienic as they are located at sites such as solid waste dumps, open drains and sewers, embankment and often along the rail line [29]. In addition, the people living in slums are extremely vulnerable to natural hazards such as floods [30]. Thus the accelerated growth of slum population fosters to the loss of expensive wetlands, vegetation cover, and also negatively affecting both human and physical environments. On the contrary, the ever-increasing urban population and its poverty result in overexploitation of natural resources to a level which is no longer sustainable for future.

\section{Conclusion}

Land use/cover classification of Dhaka City Corporation of Bangladesh using remote sensing and GIS was described in this study. Landsat images of Dhaka city of year 1990, 2003 and 2010 are analyzed by moderately accurate Interactive Supervised Classification Toolbar in ArcGIS 10. Interpreting the obtained land cover classification images and land cover areas of four land cover types (i.e. built-up, vegetation and cultivated land, water bodies and wetland, bare soil/landfill) over 1990-2010, land cover change pattern of Dhaka city is found. Un-planned increase in built-up areas and urbanization induced landfills, snatches the vegetative and cultivated lands, water bodies and wetlands, which is environmentally not sustainable. The causes of this kind of resource diminishing urbanization are considerable amount of migration from rural due to blooming opportunities, un-planned development, political crisis, poor legislative actions and inadequate policies.

\subsection{Major Findings}

$>$ In last two decades (1990-2010), built-up area has increased near 67\% and most of it (i.e. 53\%) had increased during 1990-2003. The reduced rate of growth of built-up area in last decade clearly indicates the saturation of built-up area of Dhaka City Corporation.

$>$ A mass reduction (i.e. 59\%) in vegetation and cultivated land is observed, which is alarming.

$>$ Induced landfill for infrastructural development, results in decrease of water body and wetlands (i.e. 53\%) with the increase in bare soil/landfill (i.e. $44 \%$ ).

$>$ Urbanization is the prime dominant factor affecting land use pattern change.

\subsection{Recommendations for Further Study}

$>$ Feasibility analysis of mixed-use land use pattern for Dhaka city.

> Using the findings of this study, to prepare a City Development Plan, where infrastructural development and management, environmental sustainability and ecological balance are maintained.

$>$ Future prediction of land use pattern change.

$>$ Any kind of research on pollution or individual land covers type in Dhaka city. 


\section{Acknowledgement}

We are very grateful to Md. ESRAZ-Ul-Zannat, GIS/RS Specialist, Information \& Communication Technology (ICT) Division, Institute of Water Modelling (IWM), Bangladesh; for his technical support.

Our heartfelt thanking goes to Dr. Afzal Ahmed, Associate Professor and Dean, School of Computer Science and Engineering, University of Information Technology \& Sciences (UITS), Bangladesh; for his initial encouragement for conducting this study and helping us developing the study proposal and to Sheikh Md. Nomaan, Lecturer, UITS, Bangladesh; for his throughout guidance.

\section{References}

[1]. E. L'opez, G. Bocco, M. Mendoza and E. Duhau, Predicting land-cover and land-use change in the urban fringe: a case in Morelia city, Mexico, Landscape and Urban. Planning, 55, 2001, 271-285.

[2]. A. G. Aguilar, P. M. Ward and C. B. Smith, Globalization, regional development and mega-city expansion in Latin America: Analyzing Mexico City's peri-urban hinterland, Cities, 20(1), 2003, 3-21.

[3]. D.A. Stow and D.M. Chen, Sensitivity of multi-temporal NOAA AVHRR data of an urbanizing region to land-use/land cover changes and misregistration, Remote Sens. Environ, 80, 2002, 297-307.

[4]. P.R. Coppin, and M.E. Bauer, Processing of multitemporal Landsat TM imagery to optimize extraction of forest cover change features, IEEE Transactions on Geoscience and Remote Sensing, 32, 1994, 918-927.

[5]. J.B. Collins, and C. E. Woodcock, An assessment of several linear change detection techniques for mapping forest mortality using multitemporal Landsat TM data, Remote Sensing of Environment, 56, 1996, 66-77.

[6]. S. Gopal, and C. E. Woodcock, Remote sensing of forest change using artificial neural Networks, IEEE Transactions on Geoscience and Remote Sensing, 34, 1996, 398-404.

[7]. R.D. MacLeod, and R. G. Congalton, A quantitative comparison of change-detection algorithms for monitoring eelgrass from remotely sensed data, Photogrammetric Engineering and Remote Sensing, 64, 1998, 207-216.

[8]. M. Herold, N.C. Goldstein, and K.C. Clarke, The spatiotemporal form of urban growth: measurement, analysis and modeling, Remote Sensing of Environment, 86, 2003, 286-302.

[9]. W.L. Stefanov, M.S. Ramsey, and P.R. Christensen, Monitoring urban land cover change: an expert system approach to land cover classification of semiarid to arid urban centers, Remote Sensing of Environment, 77, 2001, 173-185.

[10.] E.H. Wilson, J.D. Hurd, D.L. Civco, M.P. Prisloe, and C. Arnold, Development of a geospatial model to quantify, describe and map urban growth, Remote Sensing of Environment, 86, 2003, 275-285.

[11]. D. Müller, and M. Zeller, Land-use dynamics in the Central Highlands of Vietnam: A spatial model combining village survey data and satellite imagery interpretation, Agricultural Economics 27(3), 2002, 333-354.

[12]. Q.H. Weng, Land use change analysis in the Zhujiang Delta of China using satellite remote sensing, GIS and stochastic modeling, Journal of Environmental Management, 64, 2002, 273-284.

[13]. W.M.F. Grey, A.J. Luckman, and D. Holland, Mapping urban change in the UK using satellite radar interferometry, Remote Sensing of Environment, 87, 2003, 16-22.

[14]. Bangladesh Bureau of Statistics (BBS), Statistical Year Book of Bangladesh 2011 (Bangladesh Bureau of Statistics, Planning Division, Ministry of Planning, Government of the People's Republic of Bangladesh, Dhaka, 2012).

[15]. Bangladesh Bureau of Statistics (BBS), Statistical Year Book of Bangladesh 2005 (Bangladesh Bureau of Statistics, Planning Division, Ministry of Planning, Government of the People's Republic of Bangladesh, Dhaka, 2006).

[16]. World Bank, Dhaka, improving living conditions for the urban poor (Dhaka: The World Bank Office, Dhaka, 2007).

[17]. A.M. Chowdhury, and S. Faruqui, Physical growth of Dhaka City, In S.U. Ahmed (Ed.) Dhaka, past, present and future, The Asiatic Society of Bangladesh, Dhaka, 1989, 43-61.

[18]. N. Islam, Dhaka from city to megacity: perspectives on people, places, planning and development issues (Urban Studies Program, Dhaka, 1996).

[19]. S. Hasan, and G. Mulamoottil, Environmental problems of Dhaka City: a study of mismanagement, Cities, 11(3), 1994, 195-200.

[20]. H. Alphan, Land use change and urbanization in Adana, Turkey, Land Degradation and Development, 14(6), 2003, 575-586.

[21]. P. Basak, Spatio-Temporal Treads and Dimensions of Urban Form in Central Bangladesh: A GIS and Remote Sensing Analysis, Master's thesis, Department of Urban and Regional Planning, Bangladesh University of Engineering and Technology (BUET), Dhaka, Bangladesh, 2006.

[22]. P. Griffiths, P. Hostert, O. Gruebner, and S.V.D. e Linden, Mapping Mega City Growth with Multi-Sensor Data, Remote Sensing of Environment, 114, 2010, 426-439.

[23]. A.M. Dewan, and Y. e Yamaguchi, Landuse and Land Cover Change in Greater Dhaka, Bangladesh: Using Remote Sensing to Promote Sustainable Urbanization, Journal of Applied Geography, 29, 2009, 390-401.

[24]. B. Ahmed, Urban Land Cover Change Detection Analysis And Modeling Spatio- Temporal Growth Dynamics Using Remote Sensing And GIS Techniques, A Case Study Of DHAKA, BANGLADESH, Dissertation submitted in partial fulfillment of the requirement for the degree of masters of science in geo-spatial technologies, estfälische Wilhelms-Universität Münster (WWU), Institute for geotecrmatics (ifgi), Münster, Germany.

[25]. J. R. Eastman, IDRISI Taiga Tutorial (Manual Version 16.02) (Massachusetts, USA: Clark Labs, Clark University, 2009).

[26]. Geospatial Data Service Centre, URL:http://gdsc.nlr.nl/gdsc/information/earth_observation/band_combinations, retrieved on 03-102010, Netherlands, 2008.

[27]. Canada Centre for Remote Sensing, Fundamentals of Remote Sensing: A Remote Sensing Tutorial (Natural Resources Canada, 588 Booth Street, Ottawa, Ontario, K1A 0Y7, Canada, 2010)

[28]. Center for Urban Studies, NIPORT, National Institute of Population, Research and Training \& Measure Evaluation, Slums in Urban Bangladesh (Mapping and Census, Dhaka: CUS, 2005).

[29]. UN-Habitat, Planning Sustainable Cities: Global Report on Human Settlements, (Earthscan Publications Ltd, UK and USA, 2003).

[30]. S. F. Rashid, The urban poor in Dhaka city: their struggles and coping strategies during the floods of 1998, Disasters, 24(3), 2000, 240-253. 